\title{
Does more detailed information mean better performance? An experiment in information explicitness
}

Article

Accepted Version

Shang, Z., Brooks, C. and McCloy, R. (2014) Does more detailed information mean better performance? An experiment in information explicitness. Review of Behavioural Finance, 6 (2). pp. 86-103. ISSN 1940-5979 doi:

https://doi.org/10.1108/RBF-10-2013-0036 Available at https://centaur.reading.ac.uk/38398/

It is advisable to refer to the publisher's version if you intend to cite from the work. See Guidance on citing.

Published version at: http://dx.doi.org/10.1108/RBF-10-2013-0036

To link to this article DOI: http://dx.doi.org/10.1108/RBF-10-2013-0036

Publisher: Emerald

All outputs in CentAUR are protected by Intellectual Property Rights law, including copyright law. Copyright and IPR is retained by the creators or other copyright holders. Terms and conditions for use of this material are defined in the End User Agreement.

www.reading.ac.uk/centaur 
Central Archive at the University of Reading

Reading's research outputs online 
NOTICE: This article is (C Emerald Group Publishing and permission has been granted for this version to appear here. Emerald does not grant permission for this article to be further copied/distributed or hosted elsewhere without the express permission from Emerald Group Publishing Limited.

The definitive published version appeared in the Review of Behavioral Finance 6(2), 86-103. and is available at http://www.emeraldinsight.com/doi/pdfplus/10.1108/RBF-10-2013-0036, DOI: http://dx.doi.org/10.1108/RBF-10-2013-0036 


\title{
Does More Detailed Information Mean Better Performance?
}

\section{An Experiment in Information Explicitness}

\author{
Zilu Shang \\ ICMA Centre, University of Reading \\ Chris Brooks* \\ ICMA Centre, University of Reading \\ Rachel McCloy \\ School of Psychology and Clinical Language Sciences
}

\section{Structured Abstract}

Purpose: Investors are now able to analyse more noise-free news to inform their trading decisions than ever before. Their expectation that more information means better performance is not supported by previous psychological experiments which argue that too much information actually impairs performance. This study examines whether the degree of information explicitness improves stock market performance.

Design/methodology/approach: An experiment is conducted in a computer laboratory to examine a trading simulation manipulated from a real market-shock. Participants' performance efficiency and effectiveness are measured separately.

Findings: The results indicate that the explicitness of information neither improves nor impairs participants' performance effectiveness from the perspectives of returns, share and cash positions, and trading volumes. However, participants' performance efficiency is significantly affected by information explicitness.

Originality/value: The novel approach and findings of this research add to our knowledge of the impact of information explicitness on the quality of decision making in a financial market environment.

Keywords: explicitness of information, performance effectiveness, performance efficiency, individual investors, experimental finance.

Paper type: Research paper 
* Corresponding author: Chris Brooks, ICMA Centre, University of Reading, Whiteknights, Reading RG6 6BA, UK; tel +44 118378 7809; fax: +44 118931 4741;

C.Brooks@ @eading.ac.uk

Acknowledgements: We would like to thank Phil Holmes, co-editor of this journal, and Ioannis Oikonomou for useful comments that improved a previous version of this paper.

Biographies:

Zilu Shang is a Doctoral Candidate at the ICMA Centre, University of reading, Whiteknights, Reading, RG6 6BA, UK; tel +44 118378 7809; fax: +44 118931 4741;

Z.Shang@icmacentre.ac.uk

Chris Brooks is Professor of Finance and Director of Research at the ICMA Centre, University of reading, Whiteknights, Reading, RG6 6BA, UK; tel +44 118378 7809; fax: +44 118931 4741; C.Brooks@ reading.ac.uk

Rachel McCloy is a Lecturer in the School of Psychology and Clinical Language Sciences, University of Reading, Earley Gate, Whiteknights Road, Reading RG6 6AL; tel: +44 118378 6027; r.a.mccloy@ reading.ac.uk 


\section{Introduction}

To survive in the stock markets, individual investors struggle to interpret the information delivered by listed companies, the media, and rumours. Ambitious managers are prone to make their judgements based on how a piece of information is disclosed (Skinner, 1994; Kasznik and Lev, 1995). Rumours from online chat boards are also informative in some cases (Antweiler and Frank, 2004; Clarkson et al., 2006), while regulators have acted to eliminate information asymmetries from financial markets for several decades by improving regulatory and encouraging voluntary disclosures. Together with the rapid development of communication technology, individual investors, if they wish, are now able to collect a range of information to support their decisions. However, does more information always mean better performance for individual investors? According to previous studies, the answer is not definitive.

This paper addresses the question of whether individual investors would benefit from analysing explicit information about an uncertain event in a stock market. It is based on an experimental stock market in which all information is noise-free and participants have news about the same unexpected event but at only two levels of explicitness (implicit and explicit). More precisely, participants face a negative event arising from an accident which is unexpected and can potentially have negative effects on share prices and on the manipulated company's long-term operating performance. For some participants, who are selected randomly, relevant situations are explained by a piece of news which only states the objective facts of the accident in a general manner (implicit information). The other participants are informed by another piece of news which includes not only the objective facts but also several accurate analysts' forecasts about the effects of the accident on the manipulated company's strategic choices (explicit information). The experiment's results are analysed to examine whether participants, who act as individual investors, could realise better performances when they are informed by explicit information than by implicit information regarding an uncertain situation in an informationally efficient stock market.

\section{Literature Review}

Better information - which means more accurate, relevant, and timely information - is believed to promote market efficiency and to help investors to realise better performance (Ackert et al., 2002). Regulators have not successfully removed information asymmetries from financial markets (Aboody and Kasznik, 2000; Kothari et al., 2008; Ivashina and Sun, 2011) so that investors have to make decisions according to information at differing levels of both quantity and quality. Inconsistent with regulators' optimistic expectations, several studies show that more information is not always better (Huber et al., 2008; Joyce, 2008). In the majority of previous studies, "better information" is usually defined as a larger quantity of relevant information about the subject which is under investigation. However, the experiment presented in this paper does not examine the relationship between the quality of information (relevant versus noisy information) and investors' performance. This variable is controlled by 
excluding noise from experimental news. Instead, it is the potential interaction between the quantity of noise-free information and investors' performance that is analysed. The core question addressed by this trading experiment is whether information explicitness affects investors' decision-making processes and their decision-implementing processes. In this context, although additional information intrinsically has a positive marginal value, the extra costs expended by searching for and analysing it might eventually drive investors' returns down, theoretically, to the average level. Accordingly, in this experiment, participants in both groups contribute the same amount of resources, both physically and mentally, to collecting information concerning a negative event that occurs. To control their costs of collecting information, all relevant information about the manipulated market-shock is provided to participants directly. They only need to collect envelopes from an experimenter and open them when they are allowed to read the news. They do not have the time or access to search for extra information by themselves.

Besides the increase in costs, the negative relationship between the quantity of relevant information and investors' performance might also be explained by their limited information processing capabilities. Because of this limitation, psychologists believe that the relative information load, rather than the absolute quantity of information, is crucial in determining how efficiently decision makers can process information (Schroder et al., 1967). There should be an optimal level of information load, at which a decision maker's performance is also optimised (Eppler and Mengis, 2004). Before this optimal point (information underload), a decision maker should benefit from an increase in the quantity of relevant information. After this point (information overload), the decision maker starts to be disadvantaged by increasing relevant information.

From another perspective, the quantity of relevant information - for example concerning an uncertain event - could increase because more repeated information and/or more diversified information is available in the stock market. Repeated and diversified information do not drive a decision-maker's decision quality in the same direction. According to Iselin (1988), repeated information, by increasing the representativeness of an event, positively affects decision quality, while diversified information negatively affects decision time but not decision quality (Iselin, 1989). Accordingly, in this experiment, implicit information is unpacked into its subcomponents (explicit information) so that one of the potential outcomes, which is also the final strategy chosen by the manipulated company, is emphasised by repetition supported by various credible reasons. The quantity of noise-free information in a piece of news is defined as the level of explicitness in this study. Two levels of information explicitness - implicit information and explicit information - are tested by this experiment. Because participants only trade one stock and there is only one market-shock which might affect share prices unexpectedly, participants' information processing loads are expected not to reach the overload level. The participants who control the detailed information (explicit information) are thus expected to outperform those who analyse general objective information (implicit information).

Extending previous studies in this area that measure investors' performance mainly by their returns or risk-adjusted returns, in this paper investors' trading-related decisions are also 
tested from several other perspectives when they face different levels of information explicitness concerning an uncertain event. For example: the time that they spend on making decisions to enter their first orders, the directions of their orders as reactions to an unanticipated event, and the volume traded in their first post-market-shock order. More importantly, this experiment is conducted via a trading simulation trying to manipulate what might really occur in a stock market, from market performance to investors' psychological pressures. Share price movements mimic the performance of BP, a real company listed on the London Stock Exchange (LSE). Additionally, the shocking story tested is a replica of a real accident that happened on one of BP's manufacturing platforms in the Gulf of Mexico. Besides reconstructing the market situation when the news of BP's accident broke, participants' emotional pressures are simulated to capture what they might suffer in reaction to BP's story.

\section{Methodology}

\subsection{Trading Rules - Market, Orders Execution, and Investors}

This trading experiment is operated in a manipulated single-stock equity market which is supported by a trading simulation developed especially for this experiment. There are several trading rules in this manipulated market, based on which the trading environment is made less complex. The manipulated market itself is leverage-free. Participants cannot borrow money or shares, which means that they can buy additional shares (sell shares) if and only if they have enough cash to pay for them (they have enough shares in their account to be sold). In this leverage-free market, the risk caused by price volatility borne by participants is not magnified. Therefore, participants do not need to allocate their limited information processing capabilities to consider that, for instance, when the leverage is ten times, if the share price decreases by $10 \%$ they would lose all their investment. Participants are expected to shoulder lower levels of pressure in a leverage-free than in a leveraged market. However, to fulfil their potential purchasing or selling requirements at the very beginning of the experiment, participants are given 10,000 shares and $£ 100,000$ cash in their initial accounts. They have limited time to translate their forecasts about the uncertain event into actions and they are not allowed to transfer any shares before or after the permitted trading periods. Last but not least, this manipulated market complies with the $\mathrm{EMH}$, according to which market information will be reflected immediately in prices when it becomes publicly available.

[Take in Figure 1 here]

Regarding the methods which participants can use to trade in this manipulated market, they have two choices. Participants are able to purchase or sell shares by placing either market orders or limit orders. Market orders allow participants to purchase or sell shares immediately at the latest market price. The trading simulation executes a market order at the first price after it is entered. Limit orders allow participants to purchase or sell shares at a specified price. The simulation executes a sell (buy) limit order when the market price is equal to or higher (lower) than the required sale (purchase) price. In this experiment, another difference between a 
market order and a limit order is the chance to correct previous decisions. Once a market order is entered into the market, it is executed immediately. However, participants are able to cancel a limit order before it is executed if they believe that the price is going against their previous expectations. Participants, as individual investors, act as price takers rather than price makers and cannot observe the decisions by other participants. Therefore, the share price moves according to a pre-set price series, as shown in Figure 1. Detailed information about this price trend will be discussed in section III.2. They are informed only by the three pieces of news released during the experiment and the historic price trend.

\subsection{Participants and Procedures}

Fifty-four postgraduate students from the ICMA Centre, Henley Business School, University of Reading, UK, are equally and randomly divided into two groups (IMGroup, which is given only packed information and EXGroup, which is given unpacked information). Their average age is 23.4 and $61 \%$ of them are male. These students receive systematic training sessions about how to trade in security markets during their study. The simulation that participants use to trade in their training sessions and the one developed for this experiment are fundamentally the same. Additionally, this experiment is conducted at the end of the term, when they are expected to have sufficient knowledge about how to properly analyse the information released by the media during the experiment and to be able to make forecasts about uncertain future price performance according to their analysis, rather than betting randomly.

This experiment is composed of four stages, which are the introduction to the experiment, the first trading period, a short break, and the second trading period. At the very beginning of the experiment, three letters are handed out to participants. These letters are the introduction to the experiment and the trading simulation, News A (Appendix I) which is released at the beginning of the first trading period, and News B (Appendix II) which is released during the short break between two trading periods. News A and News B are sealed in envelopes so that participants cannot read them until they are allowed to open the envelopes. News C, which tells participants that Company SDX has decided to cancel the previously declared £2 dividend, is disclosed one minute before the end of the experiment so that participants are also completely shielded from this news until then.

\section{Step 1: Introduction to the trading stimulation}

Before handing out the letters and loading the trading simulation, an experimenter outlines the purposes of the experiment, which is to observe individual investors' trading behaviour in stock markets. The experimenter also informs participants that three letters will be distributed but they should not open any of them until they are told to do so. After distributing the envelopes, participants are guided to load the trading simulation on their computers. Then they are required to open only the envelope which is labelled "INTRODUCTION". They have three minutes to read this letter which contains 350 words in total. Following that, the experimenter explains how to trade with the trading simulation, the trading rules (described in section III.1) with which they have to comply, and the process of 
the experiment.

Before moving on to the next step, the experimenter asks for clarifying questions and these are answered privately. More importantly, the experimenter reminds participants that they should do their best to maximise their profits during the experiment and the one who earns the highest profits in each group will win a large box of luxury chocolates.

\section{Step 2: Trading with identical information News A - the control stage}

After the introduction stage, participants are notified that they will have only one minute to read News A (Appendix I), to think about the possible price movements related to this piece of news, and to make decisions about their reactions toward the possible price movements. Then, participants are allowed to open the envelopes which are labelled "Version A, News A" (for the IMGroup) or "Version B, News A" (for the EXGroup). News A is composed of forty-five words of text and two figures. The text states a dividend declaration made by Company SDX and the figures show Company SDX's annual dividend payments, basic earnings per share (basic EPS), and cash flows from operation (CFO) in the previous twelve years. Although they are labelled differently, the two versions of News A have exactly the same ingredients. Afterwards, participants start the simulation at the same time and trade according to their forecasts of News A. News A is the only piece of news released during this trading period and the price performance during this period is shown by the "First Round Trading" section in Figure 2. During this period, the opening price is $£ 10$ per share and the closing price is $£ 10.22$ per share, so that the period return is $2.2 \%$.

This trading stage is designed as a control stage. The differences which are potentially caused by participants' personalities are controlled by examining their decisions and behaviour during this trading period. The null hypothesis is that IMGroup and EXGroup participants behave identically when they trade under identical news and an objective market environment. If this hypothesis is not rejected in this trading stage, any different behaviour found in the second trading stage should be mainly triggered by the different levels of information explicitness.

\section{Step 3: Two-minute short break and News B announcement}

At the end of the fifth minute, the share price stops moving in the following two-minute period (the "short break" section in Figure 2) between the two rounds of trading. During this break, participants are forbidden to trade any more. Instead, they read and analyse News B ("Version A, News B" for IMGroup and "Version B, News B" for EXGroup). The prototype for News B is BP's oil spill accident in the Gulf of Mexico in 2010. IMGroup's Version A, News B (the implicit news) presents objective facts about the accident and the company's financial position under the name "Company SDX" (Appendix II). ${ }^{1}$ EXGroup participants

\footnotetext{
${ }^{1}$ In this experiment, we try to reproduce the market situation after BP's accident but we do not expect participants to speculate that the underlying company is BP. However, as BP's accident is so well known, the company name is replaced by Company SDX and a general word 'accident' is stated in News B rather than 'oil spill'.
} 
have every piece of information presented to IMGroup. However, in EXGroup's Version B, News B (the explicit news), there is additional information presented by analysts' forecasts regarding Company SDX's motivation to re-tailor the dividend payment declared in News A during the first trading period. These forecasts are re-drafted from broadly read financial media which emphasise the rationale behind Company SDX cancelling its previously announced annual dividend payment, although dividend cancellation is commonly treated as an extreme negative signal in stock markets. At the end of this stage, the experimenter provides a hint to participants that the last piece of news - News C, which is about the final dividend decision made by the board of Company SDX - will be released in the "Information Window" of the trading simulation at the end of the $11^{\text {th }}$ minute.

By unpacking the dividend cancellation event through the presentation of several analysts' forecasts, the actual event is repeatedly presented to participants and this unpacking approach is expected to raise its salience (Iselin, 1988). As a consequence, EXGroup participants are expected to have a higher level of confidence in the occurrence of dividend cancellation at the end of the experiment, which determines their final profits in this informationally efficient experimental market. Meanwhile, their trading behaviour is also expected to be affected accordingly.

\section{Step 4: Trading with implicit or explicit information- the experimental stage}

The market becomes active again at the end of the seventh minute. This second trading stage lasts for another five minutes. The price performance regarding News B is shown in the "Second Round Trading" section in Figure 2. Although this market is assumed to be informationally efficient, technically, participants have twenty seconds (the simulation gap) to enter their first order before the share price crashes as a reaction to the negative information presented in News B. ${ }^{2}$ If EXGroup participants are more convinced by the analysts' forecasts about dividend cancellation and treat this as an extreme negative signal, compared with IMGroup's outlook they might hold more pessimistic opinions of the future stock performance and might thus be prone to sell a larger than normal proportion of their holdings faster. If they move quickly enough to catch the twenty-second simulation gap, EXGroup participants might be able to win the chance of outperforming the IMGgroup.

The share price will decrease gradually until the end of the tenth minute. The market then shows a trend of price recovery thereafter. The purpose of this V-shaped price pattern is to deliver an illusion of a price recovery to participants before the final news that "Company SDX announces that the $£ 2$ dividend is cancelled" (News C) is released at the eleventh minute and the shares experience another 'price cliff'. This fake price recovery is designed to challenge participants' confidence in the projections they have made according to News B. Supported by explicit news, EXGroup participants should be less affected by this trap.

If participants do not believe that the experimental market is efficient (or they believe

\footnotetext{
2 The rationality of this design is that even in a strong form efficient market where the price reflects a piece of newly released information immediately, the transaction scheme might still need a short time to reflect participants' movements.
} 
that they are able to beat the market anyway) but they believe that the influence of the accident is fundamental so that they start to rebalance their portfolios, EXGroup participants may be more willing to trade than IMGroup participants (especially immediately after the market-shock). Similar reactions might be observed if participants believe that the experimental market is efficient but not in the strong form so they treat the given information as private information (because it is released via letters rather than through the trading simulation), and they need to rebalance their portfolios. On the other hand, if participants believe that the market is efficient, treat the given information as publicly available information, and consider rebalancing their portfolios, they might postpone their reactions and they may start to move during the manipulated V-shaped price recovery and EXGroup participants may place more orders than IMGroup participants. Furthermore, if participants believe the market to be efficient, their information is publicly available, and the effect of the accident is not fundamental so that there is no need to rebalance their portfolios, they may not be active in trading, both immediately after the market-shock and during the V-shaped price recovery.

\section{Analysis of Results}

As IMGroup and EXGroup participants have access to news accompanied by different levels of information explicitness, they are expected to draw differently judged probabilities of potential dividend-cut proportions so that they generate a different expected dividend-cut. Therefore, they might suffer different levels of stress or anxiety because their final goal of maximising profits is threatened by the negative information in News B. According to utility theory, dissimilarly judged probabilities might empower EXGroup and IMGroup participants to make different decisions. However, attentional control theory (Eysenck et al., 2007) ${ }^{3}$ suggests that the level of information explicitness may affect participants' performance efficiency at a higher level of significance than their performance effectiveness. Therefore, extending the majority of previous studies which analyse investors' performance based on returns, in this paper participants' performance is measured by a set of factors that separates their performance effectiveness (returns, positions held, and first order volumes after the breaking news) from performance efficiency (reaction time of first order and numbers of orders placed to achieve the period returns).

The participants' position structures are analysed as a measure of performance effectiveness because they are not required to close their share positions at the end of each trading stage so that they may realise similar returns by bearing different levels of risk. As both returns and positions reflect the final results achieved by participants during a specific trading stage (performance effectiveness within a trading period) and they might have applied

\footnotetext{
${ }^{3}$ One of the five main hypotheses discussed by Eysenck et al. (2007, pp. 340) is that "anxiety impairs process efficiency to a greater extent than performance effectiveness on tasks involving the central executive". "Performance effectiveness" refers to the quality of performance and "performance efficiency" measures the efforts devoted to generating a certain quality of performance (performance effectiveness to effort ratio).
} 
a mood repair strategy (Steenbarger and Aderman, 1979) ${ }^{4}$ after the market-shock, their initial reactions towards a piece of breaking news (performance at a specific time point) are also analysed in this paper to evaluate their behaviour immediately after receiving the unexpected information.

\subsection{Performance Effectiveness during Trading Periods}

\subsubsection{Returns}

Participants' performance during this experiment is measured by three types of returns. They are the semi return, which reflects a participant's profitability during the first trading stage (HR); the final return, which shows a participant's profitability during the whole experiment integrating the first and the second trading stages (FR); and the semi-to-final return, which exhibits a participant's profitability in the second trading stage only (HF).

Generally, IMGroup and EXGroup participants earn positive returns during the first trading stage but lose money in the second trading stage. Compared with the market returns, ${ }^{5}$ both experimental groups underperform the market during the first trading stage when the market fluctuates and report a positive period return. Individually (Table 1), by the end of the first trading stage (HR), IMGroup participants generate $1.19 \%$ less than the $2.2 \%$ market return (t-statistic $=-17.456, \mathrm{p}<0.001)$; and EXGroup participants' average return is $1.01 \%$ lower than the market return ( $\mathrm{t}$-statistic $=-12.249, \mathrm{p}<0.001$ ). However, during the second trading stage when the market collapses because of the bad news released by Company SDX, participants in both groups outperform the market. Considering participants' performance during the second trading stage (FH) separately, on average, IMGroup participants lose $2.33 \%$ (t-statistic $=9.002, \mathrm{p}<0.001)$ and EXGroup participants lose $2.42 \%$ (t-statistic $=8.386, \mathrm{p}<$ 0.001 ) less than the market loss, which is $4.89 \%$. Throughout the whole experiment period (FR), IMGroup participants' average return is $1.23 \%$ higher than the $-2.8 \%$ market return (t-statistic $=4.220, \mathrm{p}<0.001$ ); and EXGroup participants' average return is $1.48 \%$ higher (t-statistic $=4.497, \mathrm{p}<0.001)$. Participants underperform the market when the share price increases and outperform it when the share price decreases; this can be reasonably explained by the fact that they do not invest their entire wealth in stocks.

[Take in Table 1 here]

Although participants' realised returns are significantly different from the market return, there is no statistical evidence to support a conclusion that their profitability after a shocked

\footnotetext{
${ }^{4}$ Steenbarger and Aderman (1997) support the mood-repair strategy by experiments and show that (1) with some opportunities for improvement, people tend to alter the situation trying to make it better so that they would feel better; however, (2) if it is impossible to improve the situation, they tend to bury their heads in the sand.

${ }^{5}$ Market returns are determined by the pre-set prices at the end of the first and the second trading stages. At the beginning of the experiment, the share price is $£ 10$; at the end of the first trading stage, the share price is $£ 10.22$; and at the end of the second trading stage, the share price is £9.72. Therefore, the market semi return (HR) for the first trading stage is $2.2 \%$, the market semi-to-final return for the second trading stage is $-4.89 \%$ (HF), and the market final return for the whole experiment period is $-2.80 \%$ (FR).
} 
event is significantly driven by the explicitness of available news (Table 2). IMGroup and EXGroup realise comparable average returns at the end of the first trading stage (HR: $\mathrm{SW}^{6}$ $\mathrm{t}$-statistic $=1.634, \mathrm{p}=0.108$ ), which supports their identical capability to earn profits under an identical market scenario. However, the explicit information exclusively available to EXGroup participants, which successfully predicts Company SDX's decision to cancel the previously declared dividend payment (News C), does not lead to any difference in the average returns that are realised by EXGroup and IMGroup during the second trading stage (HF: SW t-statistic $=0.241, \mathrm{p}=0.832$ ). As a consequence, IMGroup and EXGroup record similar average returns during the whole experiment $(\mathrm{FR}$ : SW t-statistic $=0.581, \mathrm{p}=0.564)$.

[Take in Table 2 here]

In summary, the null hypothesis that EXGroup participants benefit from the explicit information and earn a better return than IMGroup participants is rejected. Although EXGroup participants have more explicit information which supports the occurrence of dividend cancellation, this does not protect them from losing as much money as IMGroup participants. This is not consistent with some previous experiments on support theory which test participants' decisions directly by assuming that the significant changes in judged probabilities lead to significant changes in decisions (Tversky and Kahneman, 1983; Johnson et al., 1993). ${ }^{7}$ However, this inconsistency might result from the fact that returns measure participants' performance effectiveness, which might not be significantly affected by the stress changes triggered by different levels of information explicitness. From another perspective, the similar returns realised by IMGroup and EXGroup at the end of the second trading stage does not necessarily mean that they hold similar positions (exposure to a similar extent of risk) or that they have similar trading motivations.

\subsubsection{Positions Held}

Two components of participants' assets at the end of each trading period - cash and share positions - are examined separately to consider whether the two groups suffer different levels of risk while realising similar period returns. If EXGroup participants are sufficiently convinced by the analysts' predictions about dividend cancellation in News B, they should be more pessimistic than IMGroup participants. This might be reflected in their position structures by accumulating more risk-free cash at the end of the second trading period.

[Take in Table 3 here]

The risky component of participants' assets - share positions - is measured by the number of shares that they hold at the end of each trading period. Statistical results are reported in Table 3. At the end of the control stage, during which they deal with an identical

\footnotetext{
${ }^{6}$ Satterthwaite-Welch t-tests are used to test whether two groups of data have same means, which allows for the existence of different variances.

7 There are other experiments that examine support theory but only analyse the impacts of information explicitness on individuals' judged probabilities, but these studies fail to explain whether it affects their decisions and behaviour (Fischhoff et al., 1978; Redelmeier et al., 1995; Tversky and Koehler, 1994).
} 
information scenario, IMGroup and EXGroup participants do not hold significantly different numbers of shares ( $\mathrm{SW} \mathrm{t}$-statistic $=0.719, \mathrm{p}=0.475$ ). Therefore, their similar share holdings at the end of the second trading stage $(\mathrm{SW}$ t-statistic $=0.704, \mathrm{p}=0.484)$ indicate that the level of information explicitness does not affect participants' decisions about how many shares to accumulate during this trading period. Furthermore, if considering the second trading period only, the changes of share positions from the beginning to the end of this period are not significantly different between IMGroup and EXGroup ( $\mathrm{SW}$ t-statistic $=0.034, \mathrm{p}=0.973$ ) either. Although participants are expected to be less willing to hold risky shares when they expect a weak market in the future, they might be reluctant to realise their losses in the second trading stage (Odean, 1998), which leads to comparable numbers of shares being held by EXGroup and IMGroup participants at the end. These two variables - participants' first reaction times and first order volumes - will be examined in section IV.3.

[Take in Table 4 here]

The other component of participants' portfolios in this manipulated stock market is the cash position in their trading accounts, but we find that the level of information explicitness of News B does not significantly affect participants' decisions about how to distribute their assets between the risky shares and the risk-free cash so that, by the end of the second trading stage, they are exposed to identical levels of risk.

\subsection{Performance Efficiency during Trading Periods}

According to the results presented in the previous sections, EXGroup and IMGroup participants experience comparable performance effectiveness during a specific trading period. Therefore, placing more orders indicates that a group of participants is less efficient in generating a certain level of return. During the first trading stage, the total number of valid orders placed by IMGroup participants (Table 5) is smaller than the number placed by EXGroup participants, but the difference is only marginally significant ( $\mathrm{SW} \mathrm{t}$-statistic $=1.740$, $\mathrm{p}=0.088$ ). Nevertheless, when the valid buy and sell orders are analysed separately, IMGroup and EXGroup do not exhibit significant differences during the first trading stage (valid buy orders: $\mathrm{SW}$ t-statistic $=1.304, \mathrm{p}=0.198$; valid sell orders: $\mathrm{SW}$ t-statistic $=1.658, \mathrm{p}=0.125$ ). Therefore, we still assume that there is no intrinsic difference between IMGroup and EXGroup participants' trading motivations when they face an identical market scenario. During the second trading stage when participants in different groups are dealing with news presented at different levels of information explicitness, this factor does not significantly affect the total number of valid orders placed by participants $(\mathrm{SW}$ t-statistic $=0.397, \mathrm{p}=$ 0.692). Dealing with more explicit information does not drive EXGroup participants' trading motivations to significantly deviate from IMGroup participants'. Considering buy orders (SW $\mathrm{t}$-statistic $=0.392, \mathrm{p}=0.697)$ and sell orders ( $\mathrm{SW}$ t-statistic $=1.392, \mathrm{p}=0.170)$ separately, the level of explicitness does not affect participants' buying or selling motivations either.

[Take in Table 5 here]

During the first trading stage, News A is not negative, although some investors might 
treat a continuous increase of the dividend payment as a positive signal while others might treat it neutrally. Nevertheless, the News B presented in the second trading stage (no matter how much detail it includes) is emotionally negative for investors. Besides EXGroup participants entering slightly fewer buy orders in the second trading stage (SW t-statistic $=1.897, \mathrm{p}=0.064$ ), the more negative sentiment presented by the news released during the second trading stage does not significantly influence the number of orders entered by participants in either IMGroup or EXGroup (Table 6).

[Take in Table 6 here]

\subsection{Performance at a Specific Time Point}

Participants' first reactions to news in both trading stages are measured by two variables - how soon they enter their first order into the market (reaction time) and how many shares they are willing to trade in the first order (volumes). Because EXGroup participants are expected to be more disappointed by the accident revealed by News B, they are expected to move faster than IMGroup participants. As an effect of personalities, some participants might behave more aggressively than others so that they are prone to trade a larger number of shares per order. ${ }^{8}$ However, volumes are not analysed directly; instead, the first order volume to stage volume per trade ratio (reaction volume ratio $\mathrm{FV} / \mathrm{VpT}$ ) is analysed to test the null hypothesis that EXGroup participants' reaction volume ratio more significantly deviates from one than that of IMGroup participants'. Furthermore, the stage volume per trade (VpT) of a certain trading stage does not include the first order. For example, if a participant places three orders in the first trading stage in total, the stage volume per trade for this participant during this stage is calculated according to the second and the third orders.

\subsubsection{Performance Efficiency - Reaction Time}

The less time that participants use to implement a decision, the more efficient they are. The results about the effects related to the level of information explicitness are reported in Panel A of Table 7. At the beginning of the first trading stage, when IMGroup and EXGroup are informed by exactly the same news story, they need a similar amount of time to enter their first orders ( $\mathrm{SW} \mathrm{t}$-statistic $=0.242, \mathrm{p}=0.810$ ), around half a minute from the beginning of the experiment. The level of information explicitness of News B significantly affects the time that participants spend before placing their first orders at the beginning of the second trading period ( $\mathrm{SW}$ t-statistic $=2.451, \mathrm{p}=0.018$ ). On average, EXGroup participants (24 seconds) start to move faster than IMGroup participants (65 seconds) after the negative market-shock in the second trading stage. Although there is a twenty-second simulation gap before the share price actually collapses because of the bad news, not every EXGroup participant is able to move fast enough to catch this time-gap and protect themselves from the price plunge. Specifically, $76 \%$ of IMGroup participants and $44 \%$ of EXGroup participants place their first

\footnotetext{
${ }^{8}$ For example, most participants trade shares on the basis of thousands of shares per trade, but some participants trade on the basis of hundreds or even tens of shares per trade.
} 
order in the second trading stage after the simulation gap.

[Take in Table 7 here]

Considering the first order placed by participants at the beginning of each trading stage, another variable which is worth analysing is the sentiment presented by the news - the non-negative News A versus the negative News B. Regarding the choice of time to place their first orders in the market, the results (Panel B, Table 8) indicate that the effect of news sentiment is significant among IMGroup participants ( $\mathrm{SW}$ t-statistic $=2.145, \mathrm{p}=0.037$ ) but not among EXGroup participants ( $\mathrm{SW}$ t-statistic $=0.909, \mathrm{p}=0.368)$. Inconsistent with their impaired performance efficiency during the trading period when it is measured by their mistakes, EXGroup participants become more efficient than their IMGroup peers at the moment when an unexpected market event breaks. In the second trading stage, most EXGroup participants (61.54\%) place their first orders more quickly (on average 36.25 seconds less) than in the first trading stage. However, a much smaller proportion of IMGroup participants $(38.46 \%)$, who move faster in the second trading stage, reduce their reaction time by, on average, 17.5 seconds. Additionally, regarding the participants who move slower in the second trading stage than in the first, their average reaction time increases by 32.3 seconds and 68.69 seconds for EXGroup and IMGroup, respectively.

\subsubsection{Performance Effectiveness - Reaction Volume}

The reaction volume ratio $\mathrm{FV} / \mathrm{VpT}$ evaluates participants' performance effectiveness at the moment when they read the news. Participants' FV/VpT ratios are analysed by using a "+" for a buy order and a "-" for a sell order to take the transaction direction into consideration (DRC $(\mathrm{FV} / \mathrm{VpT})$ ) to evaluate whether their integrated trading decisions, which combine the directions of orders (buy or sell) and the volumes, are different at the two levels of information explicitness. A positive (negative) average DRC (FV/VpT) ratio indicates that abnormally more shares are bid (sold) by participants in their first orders.

During the first trading stage, when participants in IMGroup and EXGroup have the same non-negative market information, the DRC (FV/VpT) ratios are significantly larger than zero (IMGroup: t-statistic $=4.187, \mathrm{p}<0.001$; EXGroup: -statistic $=2.390, \mathrm{p}=0.025$ ). They are more willing to purchase shares than at other points of time in the first trading stage, which might reflect their positive outlook regarding future stock performance. Respectively, $88.46 \%$ of IMGroup participants and $92.31 \%$ of EXGroup participants place bid orders as their first movement in the market. Indistinguishable DRC $(\mathrm{FV} / \mathrm{VpT})$ ratios $(\mathrm{SW}$ t-statistic $=$ $0.258, p=0.798$ ) in the first trading stage confirm that IMGroup and EXGroup participants' first orders at the beginning of this trading stage are similar by integrating the volumes and the direction in which they trade (Panel A, Table 8).

During the second trading stage, when participants have negative news, the DRC $(\mathrm{FV} / \mathrm{VpT}$ ) ratios turn significantly smaller than zero (IMGroup: t-statistic $=-3.016, \mathrm{p}=0.006$; EXGroup: t-statistic $=-4.998, \mathrm{p}<0.001)$. This change is also shown by the significant effects caused by information sentiment on participants' DRC (FV/VpT) ratios, which are shown in Panel B of Table 8 (IMGroup: SW t-statistic $=4.798, \mathrm{p}<0.001$; EXGroup: SW t-statistic $=$ 
4.391, $\mathrm{p}<0.001)$.The majority of IMGroup and EXGroup participants, $73.08 \%$ and $88.46 \%$ respectively, decide to sell their holdings. However, the DRC (FV/VpT) ratios are insignificantly different (the first panel of Table 8) between IMGroup and EXGroup at this stage $(\mathrm{SW}$ t-statistic $=0.179, \mathrm{p}=0.859)$, which shows that the level of information explicitness does not significantly affect participants' integrated trading decisions in their first reaction orders after the negative-market shock.

[Take in Table 8 here]

\section{Discussion and Conclusion}

By operating a trading experiment concerning a negative market-shock in a manipulated stock market, this study addresses a core question: whether the level of information explicitness regarding an uncertain event powerfully drives investors' decisions and behaviour. The results regarding participants' performance are not completely consistent with previous experiments on support theory, which assume that judged probabilities significantly affect human behaviour so that they test subjects' decisions directly and confirm the significant effects of level of information explicitness on behaviour (Tversky and Kahneman, 1983; Johnson et al., 1993). The results show that, through a trading period, explicit information marginally impairs participants' performance efficiency so that they tend to make more mistakes. On the other hand, at the point when breaking news is available, it improves their performance efficiency since participants move faster as they react to a piece of unexpected bad news. However, there is no significant evidence to support the existence of different performance effectiveness, either during a period (returns and holding positions) or at a specific point in time (first order volume to stage volume per trade ratio), between those participants who have implicit or general information about a negative uncertain event and those who have explicit or detailed information about the same event.

Although attentional control theory (Eysenck et al., 2007) might explain the integrated result that the level of information explicitness of breaking bad news drives participants' performance efficiency but not effectiveness, this might also be a result of participants' reluctance to realise losses (Odean, 1998). With the explicit version of news, participants are able to make and implement decisions in a shorter time. However, this does not sufficiently prevent their stock positions moving from winners to losers when the share price collapses. There is a conflict between participants' pessimistic perception of further losses and their intrinsic unwillingness to sell a loser, especially a large loser. In this experiment, they do evaluate their personal information and move accordingly when the winner threatens to become a loser in the future, but it seems that their rational forecasts are overwhelmed when the winner actually becomes a loser. They delay or stop selling their holdings afterwards and even start to re-build share positions at the end of the false price recovery period. As a consequence, they do not lose less money than those who receive the implicit version of the news about the same accident.

Another conclusion from these experimental results is that participants might "herd" in 
the market even in this experiment when they theoretically know nothing about who controls the market or other participants' activities. In this experimental stock market, participants who have information at different levels of explicitness tend to take similar actions at different timing points. On average, EXGroup participants move faster than IMGroup participants but their decisions are fundamentally similar so that, superficially, the IMGroup imitates the EXGroup. A typical characteristic of herding is that groups of investors behave similarly in a sequence during a certain time period so that market prices exhibit a trend. Previous rational explanations of herding emphasise the role of personal information in investors' decision-making processes and the assumption that herding investors intentionally mimic their predecessors (Welch, 1992; Devenow and Welch, 1996). However, this experiment conveys the likelihood that the imitating behaviour among different groups of investors might be implemented unintentionally, especially for the similarity of their first-placed order. In this experiment, when the negative market-shock breaks, participants have to evaluate their personal information and they have no idea about other participants' decisions. They might be able to observe signals about price movements from market prices, but not the volumes. However, IMGroup and EXGroup participants' trading decisions, combining the volumes they trade and whether they buy or sell, are similar. Accordingly, herding behaviour in financial markets might also be explained by another rational motivation: in a market where investors potentially have information at different level of explicitness because of information asymmetries among them (Chan et al., 2008; Ivashina and Sun, 2011), they might achieve convergent decisions by rationally analysing personal information independently but acting on it at different times. They might behave independently but appear as if they imitate predecessors. 


\section{References}

Aboody, D. and Kasznik, R. (2000). CEO stock option awards and the timing of corporate voluntary disclosures. Journal of Accounting and Economics, Vol. 29, Issue 1, pp. 73-100.

Acker, L. F., Church, B. K., and Shehata, M. (1997). Market behavior in the presence of costly, imperfect information: experimental evidence. Journal of Economic Behavior and Organization, Vol. 33, Issue 1, pp. 61-74.

Ackert, L. F., Church, B. K., and Zhang, P. (2002). Market behaviour in the presence of divergent and imperfect private information: experimental evidence from Canada, China, and the United States. Journal of Economic Behavior and Organization, Vol. 47, Issue 1, pp.435-450.

Antewiler, W. and Frank, M. Z. (2004). Is all that talk just noise? The information content of internet stock message boards. Journal of Finance, Vol. 59, Issue 3, pp. 1259 - 1294.

Chan, K., Menveld, A. J., and Yang, Z. S. (2008). Information asymmetry and asset prices: evidence from the China foreign share discount. Journal of Finance, Vol. 63, Issue 1, pp. $159-196$.

Clarkson, P. M., Joyce, D., and Tutticci, I. (2006). Market reaction to takeover rumour in Internet Discussion Site. Accounting and Finance, Vol. 46, Issue 1, pp. 31 - 52.

Devenow, A. and Welch, I. (1996). Rational herding in financial economics. European Economic Review, Vol. 40, Issue 3-5, pp. $603-615$.

Eppler, M. and Mengis, J. (2004). The concept of information overload: a review of literature from organization science, accounting, marketing, MIS, and related disciplines. Information Society, Vol. 20, Issue 5, pp. 325 - 344.

Eysenck. M. W., Derakshan, N., Santos, R., and Clavo, M. G. (2007). Anxiety and cognitive performance: attentional control theory. Emotion, Vol. 7, Issue 2, pp. 336 - 353.

Fischhoff, B., Slovic, P., and Lichtenstein, S. (1978). Fault trees: sensitivity of estimated failure probabilities to problem representation. Journal of Experimental Psychology: Human Perception and Performance, Vol. 4, Issue 2, pp. 330 - 344.

Huber, J., Kirchler, M., and Sutter, M. (2008). Is more information always better? Experimental financial markets with cumulative information. Journal of Economic Behavior and Organization, Vol. 65, Issue 1, pp. 86-104.

Iselin, E. R. (1988). The effect of information load and information diversity on decision quality in a structured decision task. Accounting, Organization and Society, Vol. 13, Issue 2, pp. $147-164$.

Iselin, E. R. (1989). The impact of information diversity on information overload effects in unstructured managerial decision making. Journal of Information Science, Vol. 15, Issue 3, pp. $163-173$.

Ivashina, V. and Sun, Z. (2011). Institutional stock trading on loan market information. Journal of Financial Economics, Vol. 100, Issue 2, pp. 284 - 303. 
Johnson, E. J., Hershey, J., Meszaros, J., and Kunreuther, H. (1993). Framing, probability distortions, and insurance decisions. Journal of Risk and Uncertainty, Vol. 7, Issue 1, pp. $35-51$.

Joyce, P. G. (2008). Does more (or even better) information lead to better budgeting? A new perspective. Journal of Policy Analysis and Management, Vol. 29, Issue 4, pp. 945 -975.

Kasznik, R. and Lev, B. (1995). To warn or not to warn: management disclosures in the face of an earnings surprise. Accounting Review, Vol. 70, Issue 1, pp. 113 - 134.

Kothari, S. P., Shu, S., and Wysocki, P. D. (2008). Do managers withhold bad news? Journal of Accounting Research, Vol. 47, Issue 1, pp. 241-276.

Odean, T. (1998). Are investors reluctant to realize their losses? Journal of Finance, Vol. 53, Issue 5, pp.1775 - 1798.

Power, M. J. and Dalegleish, T. (1997). Cognition and Emotion: From Order to Disorder. Hove, England: Psychology Press.

Redelmeier, D., Koehler, D. K., Liberman, V., and Tversky, A. (1995). Probability judgment in medicine discounting unspecified possibilities. Medical Decision Making, Vol. 15, Issue 3, pp. 227-230.

Schroder, H. M., Driver, M. J., and Streufer, S. (1967). Human Information Processing. Holt, Rinehar and Winston, New York.

Skinner, D. J. (1994). Why firms voluntarily disclose bad news. Journal of Accounting Research, Vol. 32, Issue 1, pp. $38-60$.

Steenbarger, B. N. and Aderman, D. (1997). Objective self-awareness as a nonaversive state: effect of anticipating discrepancy reduction. Journal of Personality, Vol. 47, Issue 2, pp. $330-339$.

Tversky, A. and Kahneman, D. (1983). Extensional vs. intuitive reasoning: the conjunction fallacy in probability judgment. Psychological Review, Vol. 91, Issue 4, pp. 293 -315.

Tversky, A. and Koehler, D. J. (1994). Support theory: A nonextensional representation of subjective probability. Psychological Review, Vol. 101, Issue 4, pp. 547 -567.

Welch, I. (1992). Sequential sales, learning, and cascades. Journal of Finance, Vol. 47, Issue 2, pp. $695-732$. 


\section{Appendix I: News A in the First Trading Stage}

Company SDX announced a $£ 2$ annual dividend per common share at 20:30 yesterday. Company SDX's annual dividend payments, CFO and Basic EPS over the past 12 years are shown to participants.

\section{Appendix II: News B in the Second Trading Stage}

The "Version A, News B" for IMGroup is:

One of Company SDX's factories suffered an accident this morning which has caused serious environmental damage. Following an emergency meeting with the local government, Company SDX announced a brief agreement to create a $£ 20$ billion claim fund over the next three and a half years.

As a consequence of this agreement, the current circumstances require the Board of Company SDX to consider modifying its dividend payment declared previously and the new dividend arrangement will be released next week.

Company SDX's business continues to perform well, with cash flows from operations (CFO) expected to exceed $£ 30$ billion this year. In addition, Company SDX has over $£ 10$ billion of committed banking facilities.

The Board stated that it remains strongly committed to the payment of future dividends and delivering long term value to shareholders.

The "Version B, News B" for EXGroup is:

One of Company SDX's factories suffered an accident this morning which has caused serious environmental damage. Following an emergency meeting with the local government, Company SDX announced a brief agreement to create a $£ 20$ billion claim fund over the next three and a half years.

As a consequence of this agreement, the current circumstances require the Board of Company SDX to consider modifying its dividend payment declared previously and the new dividend arrangement will be released next week.

Company SDX's business continues to perform well, with cash flows from operations (CFO) expected to exceed $£ 30$ billion this year. In addition, Company SDX has over $£ 10$ billion of committed banking facilities.

The Board stated that it remains strongly committed to the payment of future dividends and delivering long term value to shareholders.

Investment bankers' viewpoints:

Person X, Chief Analyst at a leading bank, said: "Company SDX will surely cancel the $£ 2$ dividend in an effort to mitigate the negative publicity from this accident."

Person Y, Head of Equities at another leading bank, added that the Local Justice Department might take legal action to force the Company SDX cancel its $£ 2$ dividend.

Person Z, co-founder of a securities firm, believes that Company SDX would not be able to maintain a sufficient liquidity level in the company if it did not cancel the $£ 2$ dividend. 
Table 1 Participants' Performance Verses Market Performance

\begin{tabular}{c|ccc|ccc}
\hline & \multicolumn{3}{|c|}{ IMGroup } & \multicolumn{3}{c}{ EXGroup } \\
\hline & HR & FR & FH & HR & FR & FH \\
\hline Group Return - Market Return & $-1.19 \%$ & $1.23 \%$ & $2.33 \%$ & $-1.01 \%$ & $1.48 \%$ & $2.42 \%$ \\
t-statistic & $-17.456 * * *$ & $4.220 * * *$ & $9.002 * * *$ & $-12.249 * * *$ & $4.497 * * *$ & $8.386^{* * *}$ \\
p-value & 0.000 & 0.000 & 0.000 & 0.000 & 0.000 & 0.000 \\
\hline
\end{tabular}

A t-test is used to analyse whether participants' returns significantly differ from zero;

$* * *$ refers to the variable being significantly different from zero at the $1 \%$ level.

Table 2: Participants' Returns

\begin{tabular}{c|ccccc}
\hline & Group & Mean & Standard Deviation & t-statistic & P-value \\
\hline \multirow{2}{*}{ Semi Return (HR) } & IMGroup & $1.01 \%$ & 0.004 & \multirow{2}{*}{0.634} & 0.108 \\
& EXGroup & $1.19 \%$ & 0.004 & & \\
\hline \multirow{2}{*}{ Semi-to-Final Return (HF) } & IMGroup & $-2.56 \%$ & 0.013 & \multirow{2}{*}{0.214} & 0.832 \\
& EXGroup & $-2.47 \%$ & 0.015 & & \\
\hline \multirow{2}{*}{ Final Return (FR) } & IMGroup & $-1.57 \%$ & 0.015 & \multirow{2}{*}{0.581} & 0.564 \\
& EXGroup & $-1.32 \%$ & 0.017 & & \\
\hline
\end{tabular}

The SW t-test is used to analyse whether participants' return is significantly affected by information explicitness.

Table 3 Share Positions

\begin{tabular}{|c|c|c|c|c|c|}
\hline & Group & Mean (No. of 1000 Shares) & Standard Deviation & t-statistic & P-value \\
\hline \multirow[b]{2}{*}{ At the End of the First Trading Stage } & IMGroup & 9.553 & 6.277 & \multirow[b]{2}{*}{0.719} & \multirow[b]{2}{*}{0.475} \\
\hline & EXGroup & 8.337 & 6.260 & & \\
\hline \multirow[b]{2}{*}{ At the End of the Second Trading Stage } & IMGroup & 7.088 & 6.565 & \multirow[b]{2}{*}{0.704} & \multirow[b]{2}{*}{0.484} \\
\hline & & 5.800 & 6.991 & & \\
\hline \multirow{2}{*}{$\begin{array}{c}\text { Difference Between the First and the Second } \\
\text { Trading Stage }\end{array}$} & IMGroup & 2.465 & 8.254 & \multirow{2}{*}{0.034} & \multirow{2}{*}{0.973} \\
\hline & EXGroup & 2.537 & 7.318 & & \\
\hline
\end{tabular}

Table 4 Cash Positions

\begin{tabular}{c|ccccc}
\hline & Group & Mean (£10000) & Standard Deviation & t-statistic & P-value \\
\hline \multirow{2}{*}{ At the End of the First Trading Stage } & IMGroup & 10.252 & 6.481 & \multirow{2}{*}{0.177} & 0.244 \\
& EXGroup & 12.337 & 6.653 & & \\
\hline \multirow{2}{*}{ At the End of the Second Trading Stage } & IMGroup & 13.181 & 6.576 & 0.998 & 0.323 \\
& EXGroup & 14.880 & 6.030 & & \\
\hline \multirow{2}{*}{ Change During the Second Trading Stage } & IMGroup & 2.929 & 8.519 & 0.179 & 0.859 \\
& EXGroup & 2.543 & 7.422 & & \\
\hline
\end{tabular}


Table 5 Valid Orders - Information Explicitness

\begin{tabular}{|c|c|c|c|c|c|c|}
\hline & & & Mean (No. of Orders) & Standard Deviation & t-statistic & P-Value \\
\hline \multirow{3}{*}{ The First Trading Stage } & Buy & $\begin{array}{l}\text { IMGroup } \\
\text { EXGroup }\end{array}$ & $\begin{array}{l}3.815 \\
4.500\end{array}$ & $\begin{array}{l}1.942 \\
1.881\end{array}$ & 1.304 & 0.198 \\
\hline & Sell & $\begin{array}{l}\text { IMGroup } \\
\text { EXGroup }\end{array}$ & $\begin{array}{l}2.481 \\
3.385\end{array}$ & $\begin{array}{l}1.827 \\
2.368\end{array}$ & 1.558 & 0.125 \\
\hline & Total & $\begin{array}{l}\text { IMGroup } \\
\text { EXGroup }\end{array}$ & $\begin{array}{l}6.296 \\
7.885\end{array}$ & $\begin{array}{l}2.920 \\
3.670\end{array}$ & $1.740^{*}$ & 0.088 \\
\hline \multirow{3}{*}{ The Second Trading Stage } & Buy & $\begin{array}{l}\text { IMGroup } \\
\text { EXGroup }\end{array}$ & $\begin{array}{l}3.704 \\
3.346\end{array}$ & $\begin{array}{l}4.017 \\
2.465\end{array}$ & 0.392 & 0.697 \\
\hline & Sell & $\begin{array}{l}\text { IMGroup } \\
\text { EXGroup }\end{array}$ & $\begin{array}{l}3.185 \\
4.077\end{array}$ & $\begin{array}{l}2.185 \\
2.465\end{array}$ & 1.392 & 0.170 \\
\hline & Total & $\begin{array}{l}\text { IMGroup } \\
\text { EXGroup }\end{array}$ & $\begin{array}{l}6.889 \\
7.423\end{array}$ & $\begin{array}{l}5.430 \\
4.310\end{array}$ & 0.397 & 0.692 \\
\hline
\end{tabular}

* refers to the difference being significant at the $10 \%$ level.

Table 6 Valid Orders - Information Sentiment

\begin{tabular}{|c|c|c|c|c|c|c|}
\hline & & & Mean (No. of Orders) & Standard Deviation & t-statistic & P-Value \\
\hline \multirow{6}{*}{ IMGroup } & \multirow{2}{*}{ Buy } & First Trading Stage & 3.815 & 1.942 & \multirow{2}{*}{0.129} & \multirow[b]{2}{*}{0.898} \\
\hline & & Second Trading Stage & 3.704 & 4.017 & & \\
\hline & \multirow{2}{*}{ Sell } & First Trading Stage & 2.481 & 1.827 & \multirow{2}{*}{1.284} & \multirow{2}{*}{0.205} \\
\hline & & Second Trading Stage & 3.185 & 2.185 & & \\
\hline & \multirow{2}{*}{ Total } & First Trading Stage & 6.296 & 2.917 & \multirow{2}{*}{0.499} & \multirow{2}{*}{0.620} \\
\hline & & Second Trading Stage & 6.889 & 5.430 & & \\
\hline \multirow{6}{*}{ EXGroup } & \multirow{2}{*}{ Buy } & First Trading Stage & 4.500 & 1.881 & \multirow{2}{*}{$1.897 *$} & \multirow{2}{*}{0.064} \\
\hline & & Second Trading Stage & 3.346 & 2.465 & & \\
\hline & \multirow{2}{*}{ Sell } & First Trading Stage & 3.385 & 2.368 & \multirow{2}{*}{1.033} & \multirow{2}{*}{0.307} \\
\hline & & Second Trading Stage & 4.077 & 2.465 & & \\
\hline & \multirow{2}{*}{ Total } & First Trading Stage & 7.885 & 3.670 & \multirow{2}{*}{0.416} & \multirow{2}{*}{0.679} \\
\hline & & Second Trading Stage & 7.423 & 4.310 & & \\
\hline
\end{tabular}

* refers to the difference being significant at the $10 \%$ level. 
Table 7 First Reactions -Reaction Time

\begin{tabular}{|c|c|c|c|c|c|c|}
\hline & & & Mean (seconds) & Standard Deviation & t-statistic & P-value \\
\hline \multirow{4}{*}{$\begin{array}{c}\text { Panel A } \\
\text { Level of Explicitness }\end{array}$} & The First Trading & IMGroup & 28.96 & 22.908 & \multirow{2}{*}{0.242} & \multirow{2}{*}{0.810} \\
\hline & Stage & EXGroup & 30.84 & 31.452 & & \\
\hline & \multirow{2}{*}{$\begin{array}{c}\text { The Second Trading } \\
\text { Stage }\end{array}$} & IMGroup & 65.280 & 81.487 & \multirow{2}{*}{$2.451 * *$} & \multirow{2}{*}{0.018} \\
\hline & & EXGroup & 23.680 & 23.688 & & \\
\hline \multirow{4}{*}{$\begin{array}{c}\text { Panel B } \\
\text { Information Sentiment }\end{array}$} & \multirow{2}{*}{ IMGroup } & First Trading Stage & 28.960 & 22.908 & \multirow{2}{*}{$2.145^{* *}$} & \multirow{2}{*}{0.037} \\
\hline & & Second Trading Stage & 65.280 & 81.487 & & \\
\hline & \multirow{2}{*}{ EXGroup } & First Trading Stage & 30.840 & 31.452 & \multirow{2}{*}{0.909} & \multirow{2}{*}{0.368} \\
\hline & & Second Trading Stage & 23.680 & 23.688 & & \\
\hline
\end{tabular}

** refers to the difference being significant at the $5 \%$ level.

Table 8 First Reactions - Reaction Volume Ratio (FV/VpT)

\begin{tabular}{|c|c|c|c|c|c|c|}
\hline & & & Mean & Standard Deviation & t-statistic & P-value \\
\hline \multirow{4}{*}{$\begin{array}{c}\text { Panel A } \\
\text { Information Explicitness }\end{array}$} & The First & IMGroup & 0.653 & 0.795 & \multirow{2}{*}{0.258} & \multirow{2}{*}{0.798} \\
\hline & Trading Stage & EXGroup & 0.743 & 1.585 & & \\
\hline & \multirow{2}{*}{$\begin{array}{l}\text { The Second } \\
\text { Trading Stage }\end{array}$} & IMGroup & -0.735 & 1.242 & \multirow{2}{*}{0.179} & \multirow{2}{*}{0.859} \\
\hline & & EXGroup & -0.787 & 0.803 & & \\
\hline \multirow{4}{*}{$\begin{array}{c}\text { Panel B } \\
\text { Information Sentiment }\end{array}$} & \multirow{2}{*}{ IMGroup } & First Trading Stage & 0.653 & 0.795 & \multirow{2}{*}{$4.798 * * *$} & \multirow{2}{*}{0.000} \\
\hline & & Second Trading Stage & -0.735 & 1.242 & & \\
\hline & \multirow{2}{*}{ EXGroup } & First Trading Stage & 0.743 & 1.585 & \multirow{2}{*}{$4.391 * * *$} & \multirow{2}{*}{0.000} \\
\hline & & Second Trading Stage & -0.787 & 0.803 & & \\
\hline
\end{tabular}

*** refers to the difference being significant at the $1 \%$ level.

Figure 1 Price Trend of Company SDX's Share Price

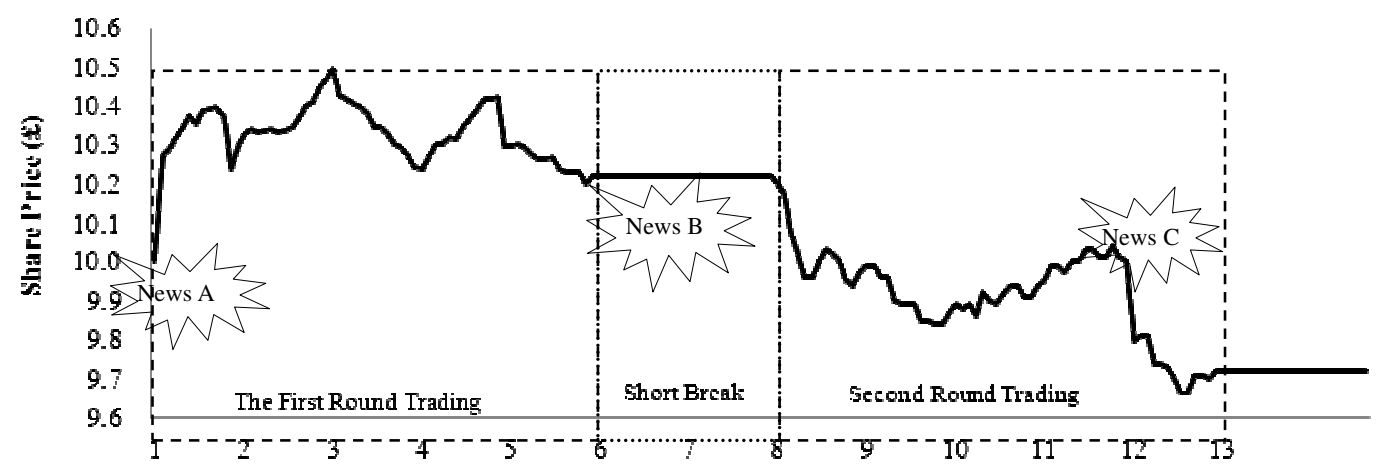

